\title{
A case of intraepithelial squamous cell carcinoma arising from urethral caruncle
}

\author{
Gou Kaneko, MD; Koshiro Nishimoto, MD; Kentaro Ogata, MD; ${ }^{\dagger}$ Atsushi Uchida, MD*
}

\section{Abstract}

A 62-year-old female patient had occasional bleeding from a mass in the urethral meatus. She had been conservatively treated with steroid ointment at another hospital for 1 year, but the bleeding had persisted. The patient was therefore referred for further treatment. A reddish mass, measuring $5 \mathrm{~mm}$ in diameter was noted at the posterior lip of the urethral meatus. The mass was diagnosed to be a urethral caruncle and was removed. Microscopically, the squamous epithelium, which covered the urethral caruncle, was found to be keratinized, with the proliferation of atypical cells with swollen nuclei in the entire mucosal layer. The mass was finally diagnosed to be intraepithelial squamous cell carcinoma arising from the urethral caruncle.

The occurrence of intraepithelial squamous cell carcinoma arising from a urethral caruncle is extremely rare. A search of the English literature revealed only 1 other case report.

Cite as: Can Urol Assoc J 2011:5(1):e14-el6; D01:10.5489/cuaj.10027

\section{Introduction}

Urethral caruncles usually arise from the posterior lip of the urethral meatus. Although the etiology of this disease has not yet been established, it is the most common benign tumour of the female urethra. ${ }^{1}$ Most cases of urethral caruncle are frequently asymptomatic, but some patients experience a lump or bleeding at the urethral meatus. The lesion is considered to be neither neoplastic nor preneoplastic, but probably results from local trauma or inflammation. ${ }^{2}$ However, carcinoma (1.6\%) and Bowen's disease $(0.8 \%)$ are extremely rarely and have been noted in $2.4 \%$ of patients with a clinical diagnosis of urethral caruncle. This report describes a case of intraepithelial squamous cell carcinoma arising from the urethral caruncle.

\section{Case report}

A 62-year-old female patient was referred to undergo the resection of a urethral caruncle. The patient had been treated with steroid ointment for a year at another hospital, but bleeding from the caruncle had still been observed occasionally. The caruncle measured $5 \mathrm{~mm}$ in diameter and was located at the posterior lip of the urethral meatus. The caruncle was resected using standard procedures. Pathologically, the squamous epithelium covered the stroma with severe edema and ectasia of the vessels (Fig. 1). Part of the urothelial epithelium had invaginated into the stroma. The squamous epithelium was partially keratinized (Fig. 2) with the proliferation of atypical cells with swollen nuclei throughout the entire mucosal layer (Fig. 3). A diagnosis of intraepithelial squamous cell carcinoma arising from the urethral caruncle was made. The surgical margin was negative. Systemic examinations, including computed tomography, were performed postoperatively and revealed only a left adrenal adenoma measuring $12 \mathrm{~mm}$ in diameter, while no abnormal findings were noted in a hormonal examination. Cystourethroscopy also revealed no abnormal lesions in either the bladder or urethra. The patient is doing well, with no signs of recurrence or distant metastasis a year after the operation.

\section{Discussion}

Urethral caruncles are the most common urethral disease among females. It is an inflammatory nodule that arises at the posterior lip of the external meatus and is commonly seen after menopause. ${ }^{3}$ The lesion consists of a connective tissue core with its surface covered by either a urothelial or squamous epithelium. ${ }^{2}$ Macroscopically, a caruncle is a nodular or pedunculated erythematous lesion that may bleed easily. ${ }^{3}$ Caruncles are uniformly benign and are not considered risk factors for subsequent neoplasia. ${ }^{4}$ Most cases are treated conservatively with topical estrogen, anti-inflammatory creams or a sitz bath. ${ }^{5}$ Large or refractory lesions may be resected surgically. 


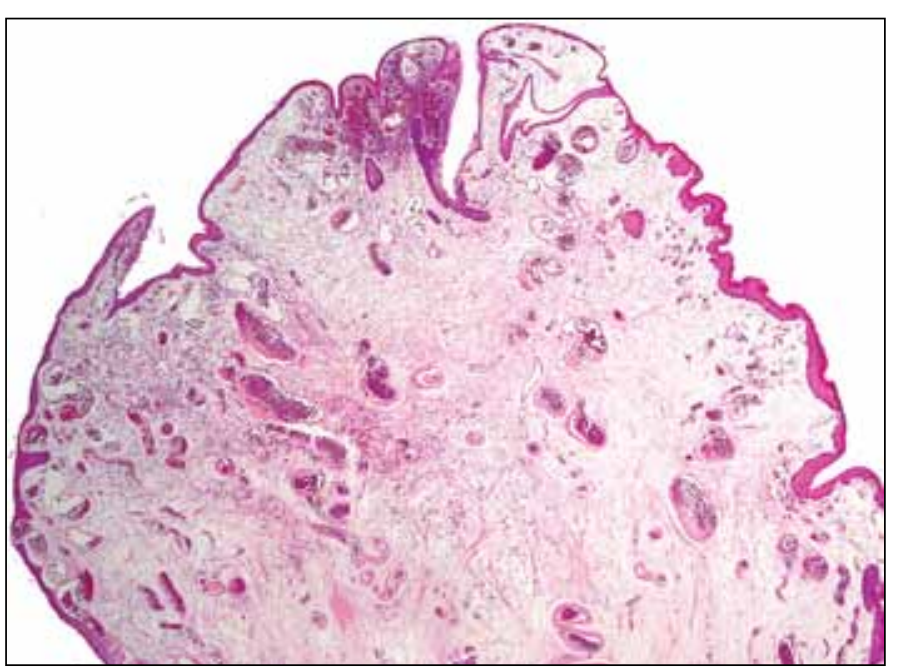

Fig. 1. The squamous epithelium covered the stroma with severe edema and ectasia of vessels (hematoxylin and eosin staining, original magnification: 20x).

The patient in this case was treated conservatively with steroid ointment, but the lesion had to be resected at a later time due to persistent bleeding. The appearance of the lesion suggested a typical urethral caruncle, but histopathologically, atypical cells with swollen nuclei proliferated throughout the entire mucosal layer of squamous epithelium. Therefore, it was finally diagnosed to be intraepithelial squamous cell carcinoma arising from the urethral caruncle. Urethral caruncles are considered to be neither neoplastic nor preneoplastic lesions. Chronic inflammation induced by an indwelling catheter, stones and other causes are risk factors of squamous cell carcinoma in patients with bladder carcinoma. Chronic irritation to the urethral caruncle might be one of the risk factors of squamous cell carcinoma, although the precise mechanism is still uncertain.

In their study, Marshall and colleagues reported that intraepithelial carcinoma coexisted with a "benign appearing" urethral caruncle in only 1 of 376 patients who underwent a urethral caruncle resection. ${ }^{6}$ This is the only report of intraepithelial carcinoma arising from a urethral caruncle found in the English literature. The present case is considered to be the second known case of this disease. There is no established treatment for intraepithelial carcinoma arising from a urethral caruncle because of its rare occurrence. We thought that the present case could be treated as distal urethral carcinoma due to its site and histological type. Urethral carcinoma in females is an uncommon neoplasm accounting for only $0.02 \%$ of all types of cancer in women 4 and only $5 \%$ of all urologic malignancies. The most common histological type is squamous cell carcinoma, accounting for up to $70 \%$ of all cases, followed by transitional cell carcinoma and adenocarcinoma. Distal urethral carcinoma tends to present at a low stage in patients with urethral carcinoma, with a cure rate between $70 \%$ and $90 \%$ with local excision alone. ${ }^{7}$ The present case is considered

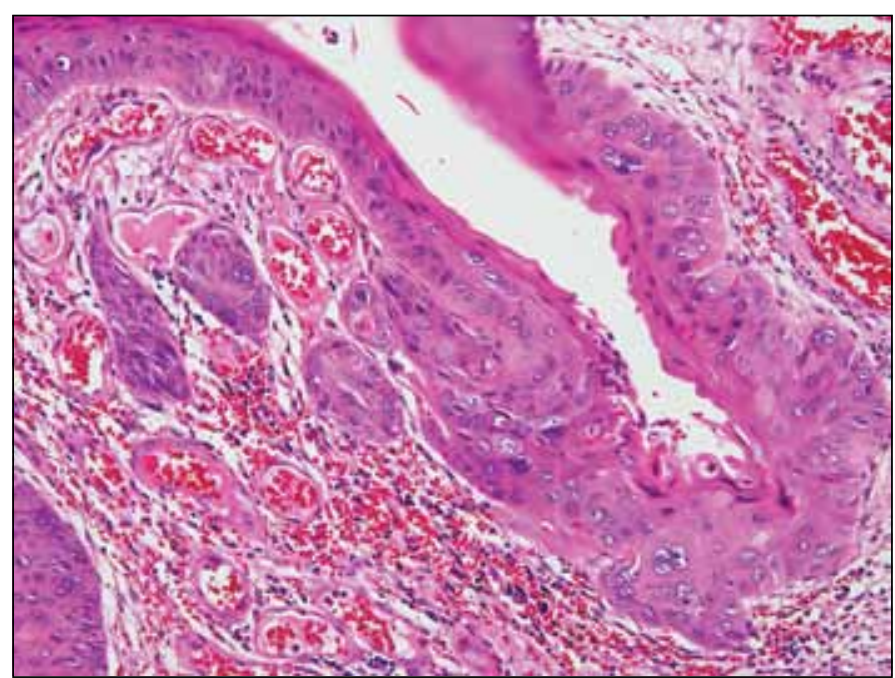

Fig. 2. The squamous epithelium of the urethral caruncle was partially keratinized (hematoxylin and eosin staining, original magnification: 200x).

to be distal urethral carcinoma, which must be carefully followed up.

Some types of neoplasms, such as Non-Hodgkin's lymphoma, malignant melanoma and ovarian tumours, have a urethral caruncle-like appearance..$^{8-10}$ Marshall and colleagues reported that $2.4 \%$ of all patients with a preoperative diagnosis of urethral caruncle were found to have either carcinoma $(1.6 \%)$ or Bowen's disease $(0.8 \%)$ in a series of 376 patients. ${ }^{6}$ Urethral carcinoma resembling a urethral caruncle is also rarely observed.

\section{Conclusion}

Urethral caruncle is a common disease, and most cases are treated conservatively. However, malignant carcinoma arising from the urethral caruncle or urethral carcinoma resem-

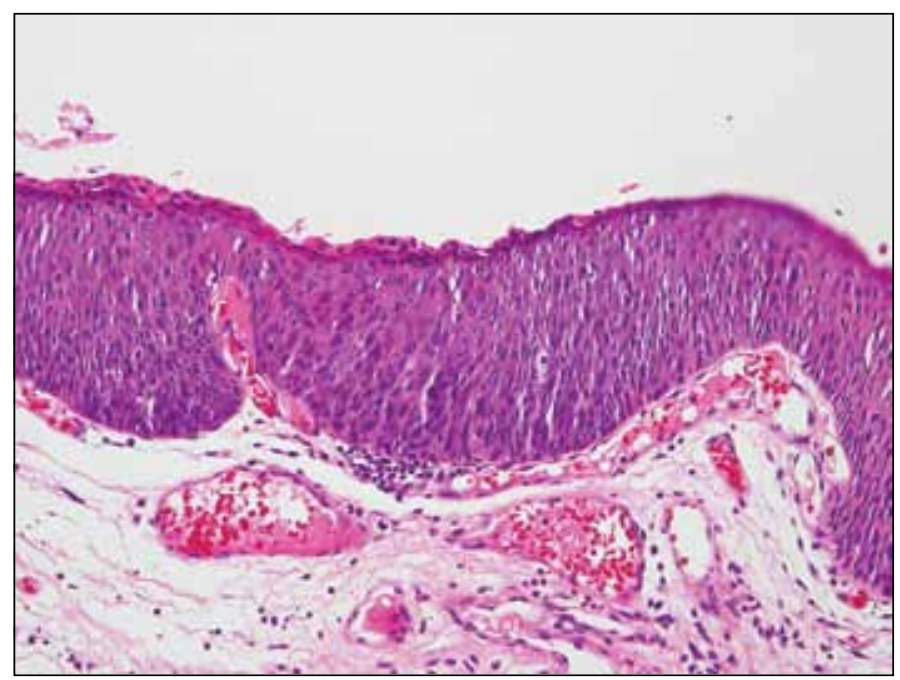

Fig. 3. Atypical cells with swollen nuclei proliferated throughout the entire mucosal layer (hematoxylin and eosin staining, original magnification: 200x). 
Kaneko et al.

bling a caruncle has only rarely been reported. Therefore, the patient's condition should be carefully monitored when conservative therapy is selected. Large or refractory caruncles and those with an unusual appearance should be aggressively surgically treated and carefully evaluated for the presence of any possible malignancy.

*Department of Urology, Kyosai Tachikawa Hospital, Tokyo, Japan; †Department of Pathology, Kyosai Tachikawa Hospital, Tokyo, Japan

Competing interests: None declared.

This paper has been peer-reviewed.

\section{References}

1. Kurmann R. Blaustein's pathology of the female genital tract. 3rd edition. New York:NY: Springer Verkag; 1987:85-7.

2. Pugh RC. The Kidneys: The Urinary Tract. Systemic Pathology. 3rd edition. Philadelphia, PA: W.B. Saunders Company; 1992:745.

3. Cimentepe E, Bayrak 0, Unsal A, et al. Urethral adenocarcinoma mimicking urethral caruncle. Int Urogynecol J Pelvic Floor Dysfunct 2006; 17:96-8.

4. Murphy. Diseases of the urinary bladder, urethra, ureters and renal pelvis. Philadelphia: PA: W.B. Saunders Company; 1997:34-147.

5. Rovner ES. Campbell-Walsh Urology. 9th edition. Philadelphia: PA: W.B. Saunders Company; 2007:2384-5.

6. Marshall FC, Uson AC, Melicow MM. Neoplasma and caruncles of the female urethra. Surg Gynecol Obstet 1960;110:723-33.

7. Sharp D, Angermeier K. Campbell-Walsh Urology. 9th edition. Philadelphia: PA: W.B. Saunders Company; 2007:993-1022.

8. Nabholtz JM, Friedman S, Tremeaux JC, et al. Non-Hodgkin's lymphoma of the urethra: a rare extranodal entity. Gynecol Oncol 1989;35:110-1.

9. Nakamoto $\mathrm{T}$, Inove $\mathrm{Y}$, Ueki $\mathrm{T}$, et al. Primary amelanotic malignant melanoma of the female urethra. Int J Urol 2007; 14:153-5.

10. Hammadeh MY, Thomas K, Philp T. Urethral caruncle: an unusual presentation of ovarian tumour. Gynecol Obstet Invest 1996;42:279-80.

Correspondence: Dr. Gou Kaneko, Department of Urology, Kyosai Tachikawa Hospital, 4-2-22, Nishikicho, Tachikawa, Tokyo, 190-8531, Japan; fax: 81-42-522-5784; gouk0901@aol.com 